\title{
(4 + 2) Cycloadditions via Pd C(sp3)-H activation
}

\author{
Xandro Vidal, Marc Font, Borja Cendón, José Luis Mascareñas, Moisés Gulías
}

\section{Peer reviewed version}

This is the peer reviewed version of the following article: Vidal, X.; Font, M.; Cendón, B.; Mascareñas, J. L.; Gulías, M. (2021), $(4+2)$ Cycloadditions via Pd C(sp3)-H activation. Trends Chem., 3(12): 1102-1103, which has been published in final form at https://doi.org/10.1016/j.trechm.2021.08.009. This article may be used for noncommercial purposes in accordance with Elsevier Terms and Conditions for Use of SelfArchived Versions.

\section{How to cite:}

Vidal, X.; Font, M.; Cendón, B.; Mascareñas, J. L.; Gulías, M. (2021), (4 + 2) Cycloadditions via $\mathrm{Pd} \quad \mathrm{C}(\mathrm{sp} 3)-\mathrm{H}$ activation. Trends Chem., 3(12): 1102-1103. doi: 10.1016/j.trechm.2021.08.009

\section{Copyright information:}

(C) 2021 Elsevier. This article may be used for non-commercial purposes in accordance with Elsevier Terms and Conditions for Use of Self-Archived Versions 


\section{Trends in Chemistry $\mid$ Mechanism of the Month}

\section{$(4+2)$ Cycloadditions via Pd $\mathrm{C}\left(\mathrm{sp}^{3}\right)-\mathrm{H}$ activation}

Xandro Vidal, ${ }^{1}$ Marc Font, ${ }^{1}$ Borja Cendón, ${ }^{1}$ José Luis Mascareñas, ${ }^{1}$ and Moisés Gulías $\mathbb{D}^{1, *}$

${ }^{1}$ Centro Singular de Investigación en Química Biolóxica e Materiais Moleculares (CiQUS), Departamento de Química Orgánica, Universidade de Santiago de Compostela, 15782 Santiago de Compostela, Spain

$\mathrm{C}\left(\mathrm{sp}^{3}\right)-\mathrm{H}$ activation and formal (4+2) cycloaddition

$\mathrm{R}^{2} \overbrace{\mathrm{NHNs}}^{\mathrm{R}^{1}}+\underbrace{\mathrm{O}}_{\mathrm{R}^{3}} \mathrm{R}_{\mathrm{R}^{4}}$

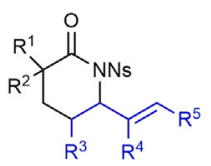<smiles>Cc1ccc2ccccc2n1</smiles>

Quinaldine

Trends in Chemistry

ORIGIN

The functionalization of aliphatic $\mathrm{C}\left(\mathrm{sp}^{3}\right)$ - $\mathrm{H}$ bonds using Pd catalysis has emerged as a powerful, step economical methodology for the construction of $\mathrm{C}-\mathrm{C}$ and $\mathrm{C}-\mathrm{X}$ bonds. Despite the progress in this field, examples of formal cycloadditions entailing this type of activation have been essentially limited to carbonylation processes. This work describes a formal (4 + 2 ) cycloaddition between alkylamides and dienes, a reaction that provides a direct, simple, and unconventional access to saturated lactams.

\section{REACTION MECHANISM}

The proposed mechanism for the $(4+2)$ cycloaddition starts with the formation of an active monomeric catalyst $(\mathbf{l a})$, with the quinaldine acting as a monodentate ligand. Because of the steric bulk of this ligand, the formation of unreactive complexes with two units of quinaldine (Ib) is disfavored. Then, facilitated by the relatively high acidity of the amide, the substrate displaces one of the acetate ligands to give the amidopalladium complex II. This complex evolves by activation of the $\mathrm{C}\left(\mathrm{sp}^{3}\right)-\mathrm{H}$ bond of the methyl group, likely based on a concerted metalation deprotonation process, to form palladacycle III. This complex has been experimentally isolated and fully characterized and, not surprisingly, it can engage in the formal (4 + 2) cycloaddition with dienes by itself, which supports its participation as intermediate in this reaction. After the $\mathrm{C}-\mathrm{H}$ activation step, the diene coordinates to the palladacycle and undergoes migratory insertion to give palladium $\pi$-allyl intermediate $\mathbf{V}$, perhaps via intermediate $\mathbf{I V}$. The $\pi$-allyl type of coordination may have a key role in stabilizing intermediate $\mathbf{V}$ and favoring a reductive elimination pathway over nondesired $\beta$-hydride eliminations. This is supported by the fact that alkynes or alkenes do not engage in this kind of $(4+2)$ cycloaddition. Finally, the resulting palladium (0) is reoxidized by copper(II) acetate to restart the catalytic cycle.

Key mechanistic findings:

1) The quinaldine ligand plays an essential role, facilitating the formation of III

2) The presence of a nosyl group in the amide is key for the success of the reaction

3) Intermediate III was isolated and demonstrated to work as substrate in the reaction.

4) Cis dienes show poor reactivity, suggesting the migratory insertion as pausible rate limiting step

5) Reaction favored by the "diene effect" (stabilization of intermediates by extra coordination). Alkynes, alkenes do not undergo the $(4+2)$ annulation.

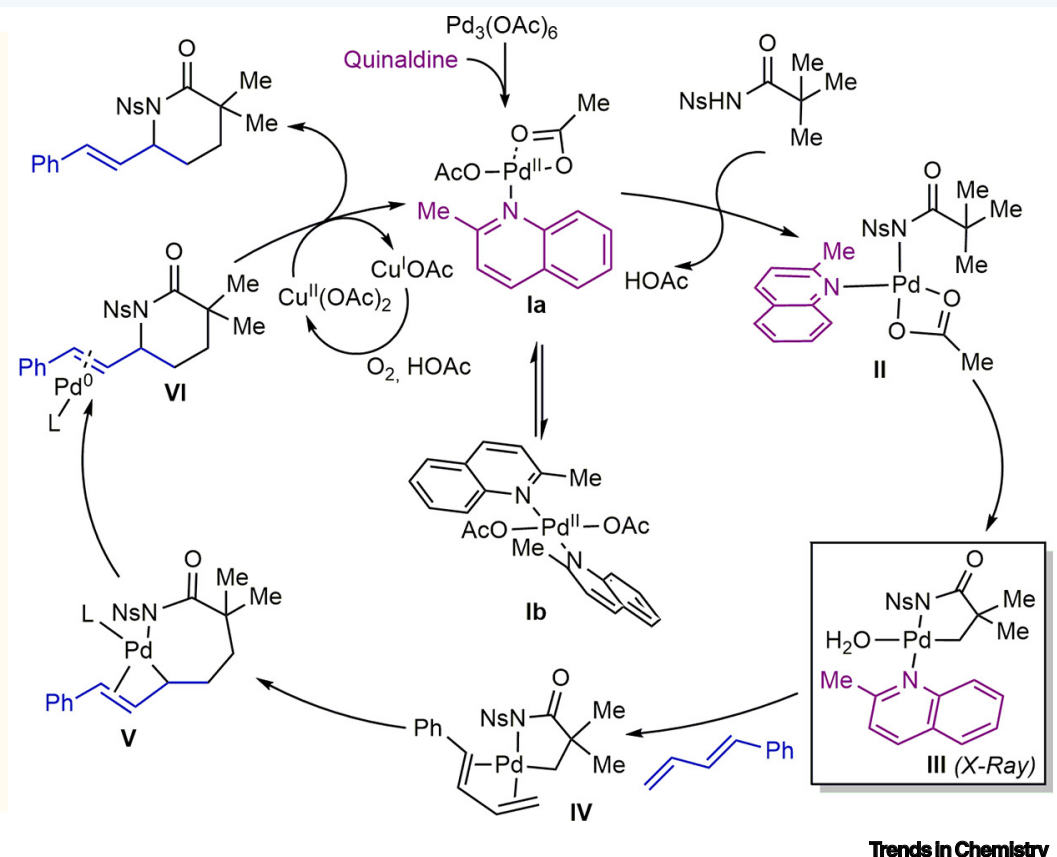

IMPORTANCE

This reaction represents the first palladium-catalyzed formal $(4+2)$ cycloaddition enabled by the cleavage of nonactivated $\mathrm{C}\left(\mathrm{sp}^{3}\right)-\mathrm{H}$ bonds, thereby proposing new avenues for the construction of heterocycles. Key for the success of the reaction is the use of a tailored quinoline as palladium ligand and dienes as cycloaddition partners.

Declaration of interests

No interests are declared.

*Correspondence: moises.gulias@usc.es (M. Gulías). 


\section{Trends in Chemistry $\mid$ Mechanism of the Month}

\section{Literature}

1. He, J. et al. (2017) Palladium-catalyzed transformations of alkyl C-H bonds. Chem. Rev. 117, 8754-8786

2. Gulías, M. et al. (2016) Metal-catalyzed annulations through activation and cleavage of C-H bonds. Angew. Chem. Int. Ed. 55, $11000-11019$

3. Yoo, E.J. et al. (2010) Pd(II)-catalyzed carbonylation of C(sp $\left.{ }^{3}\right)-H$ bonds: a new entry to 1,4-dicarbonyl compounds. J. Am. Chem. Soc. 132, 17378-17380

4. McNally, A. et al. (2014) Palladium-catalysed C-H activation of aliphatic amines to give strained nitrogen heterocycles. Nature 510, 129-133

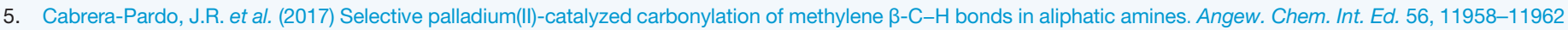

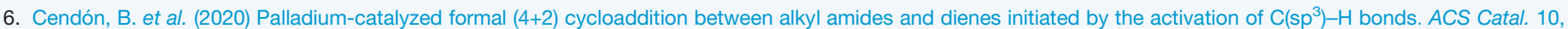
$3425-3430$

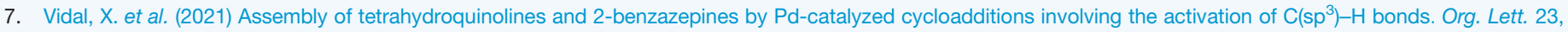
5323-5328

8. Park, H. et al. (2020) Palladium-catalyzed [3 + 2] cycloaddition via twofold 1,3-C(sp $\left.{ }^{3}\right)-H$ activation. J. Am. Chem. Soc. 142, 16552-16556

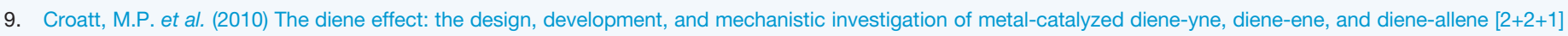
cycloaddition reactions. Eur. J. Org. Chem. 2010, 19-32

10. Gulías, M. et al. (2011) Ruthenium-catalyzed $(2+2)$ intramolecular cycloaddition of allenenes. J. Am. Chem. Soc. 133, 7660-7663 